\title{
Targeted vouchers and its effects
}

- Eduardo de Carvalho Andrade*

\section{Abstract}

This paper discusses the benefits of the "Targeted Vouchers" system in relation to the actual one. It analyses the Chilean experience and emphasizes the importance of the appropriate design of the vouchers system in order to achieve the expected results. The analyses also suggest that the implementation of this system may face opposition due to two consequences of its implementation: reduction in the welfare of specific groups and the closure of some Public universities which are less efficient. Keywords: Educational financing. Educational "Vouchers". Efficiency. Human capital

JEL Classification: HO; H41; $22 ; 128$.

\section{O Sistema de "Targeted Vouchers" e seus efeitos Resumo}

Este trabalho discute os beneficios do sistema de "targeted vouchers" vis-à-vis o atual. Ele analisa a experiência chilena e enfatiza a importância do desenho apropriado do sistema de vouchers de maneira a alcançar os resultados esperados. A análise também sugere que a introdução do sistema de "targeted vouchers" pode enfrentar oposição devido a duas conseqüências potenciais de sua implementação: a redução no bemestar de grupos especficos e o fechamento das universidades públicas menos eficientes.

Palavras-chave: Financiamento educacional. "Vouchers" educacionais. Eficiência. Capital humano.

\section{El sistema de "Targeted Vouchers" y sus efectos Resumen}

Este trabajo discute las ventajas del sistema de "targeted vouchers" vis-à-vis el actual. Analiza la experiencia chilena y destaca la importancia del diseño apropiado del sistema de vouchers para obtener los resultados deseados. EI

* Insper Institute of Education and Research. E-mail: eduardo.andrade@isp.edu.br 
análisis sugiere que la introducción del sistema de "targeted voucher" puede sufrir oposición debido a dos consecuencias potenciales de su implementación: la reducción en el bienestar de grupos especficos y del cerrado de las universidades públicas menos competitivas.

Palabras clave: Finanzas educativas. "Vouchers" educativos. Eficacia. Capital humano

\section{Introduction}

The Brazilian government heavily subsidizes higher education. Approximately $40 \%$ of all students attend public universities and the tuition is basically free. There are important reasons why this free-tuition system is not very appropriate and should be changed.

First, it is clearly regressive and does not promote equality of opportunity. It is financed through tax revenues by all individuals in the economy. However, its beneficiaries are in general students coming from high income families. The reasons are obvious. They receive a higher quality pre-university education which allows them more likely to finish high school and perform better in the competitive entrance exams for the public universities. They choose the public option over the private one either because the public universities are better or because it is not worth " paying twice" for a better education (through tax and tuition in private universities). In Brazil, $76 \%$ of all public expenditures in higher education are directed to the top 20\% richest families in the population. Only $3 \%$ are directed to the $60 \%$ poorest families?.

Second, under the presence of externalities in education, it is not necessarily optimum to subsidize every student at the same rate. Mostly important, given the financial difficulties of the governments and the potential alternative uses of the money, it is desirable to use more efficiently the public resources.

Finally, the free-tuition system is not the most efficient one. Among other things, Andrade (2008) compares it with a targeted voucher system. Under this system, public tuitions are not free. Low income students receive vouchers that can be used either to pay private or public tuition. The others have to sponsor fully their higher education ${ }^{2}$. He concludes that a targeted voucher system is clearly more efficient than a free-tuition one. It produces a higher quality of the labor force, a greater social mobility and a more efficient allocation of total resources (private and public) in higher education. Its advantage is related to the fact that it directs public resources only to those individuals who really need financial support to attend an university.

1 For details, see Veloso e Ferreira (2006).

2 Pro-poor voucher plans operate in some countries (e.g., Colombia, Guatemala, the United States), but only in lower levels of education, not in universities. To my knowledge, Chile is the only country that adopts a nationwide school choice system. Its system, however, is a universal one as proposed by Friedman (1962), not a selective one. For different funding mechanisms for higher education in the world, see Albrecht and Ziderman (1992) and Chapman (2006). 
Despite the reasons mentioned above, there has been no attempt to change the current system and there is no movement in this direction. This paper's objective is to understand why this is the case. In order to perform this analysis, I use the same model developed in Andrade (2008). I analyze which are the groups in society who are the most likely to benefit and to be hurt from a change from the current system to a targeted voucher one.

The analysis suggests that two effects combined can explain possible political oposition to the replacement of the current system by the the more efficient targeted vouchers one. On the one hand, as voucher allows its beneficiaries to select which university to attend, one consequence of its introduction is the shut down of the less competitive public universities. On the other hand, some specific groups have their welfare reduced with vouchers in comparison with the current system. It occurs either because the skill premium is lower (due to the higher quality of the labor force obtained with vouchers) or because they lose their right to attend the tuition free public universities.

There are some papers related to this one, in addition to Andrade (2008). It adapts a framework developed by Caucutt and Kumar (2003), which analyses the effects of increasing higher education subsidies in the US on inequality, welfare and efficiency. They do not examine the effects of targeted vouchers. Chen and West (2002) studies the median voter choice between the universal and selective vouchers but in primary and secondary education. In contrast with the ideas in Johnson (1984), Creedy and François (1990) and Fernandez and Rogerson (1995), the results of this paper are in line with the explanation that majority voting is not an appropriate mechanism to capture how the goverment takes its decisions and possibly political power is concentraded among wealthier individuals. If a majority voting mechanism was in place, the targeted vouchers system would replace the current one.

The paper is organized as follows. Section 2 dicusses how the replacement of the current system by a targeted voucher system in the higher education sector in Brazil may affect the quality of the labor force and social mobility. In the next section, we discuss the effects and problems of the introduction of a nationwide school choice system in Chile. The idea is to contrast the theoretical results of the previous section with the empirical evidence of the Chilean case, which has some similarities with the one proposed here to the higher education sector in Brazil. Section 4 lays out the structure of the model. The following section examines the welfare consequences of replacing the current system by the targeted vouchers one. The final section concludes. 


\section{Targeted Voucher System vs. the Current One}

In this section, we discuss some effects of the introduction of a targeted voucher system in the higher education sector in Brazil ${ }^{3}$. We argue that it is a more efficient system as it is able to increase the quality of the labor force and improve the social mobility. Initially, we discuss the main features of this system and contrast with the current one.

In the current system, there is a mix of private and public universities, with 63\% of students enrolled in private universities. The public universities are tuition-free and, on average, they have higher quality than the private ones. As the best high schools are, on average, private, its students are better qualified and are able to pass the selective exam to enter in the public universities. These students come, in general, from relatively high income families who are able to pay the private school tuitions. Students from relatively low income families, on average, who study in public schools have more difficulty in passing the entrance exams to enter in public universities and are likely to study in private universities.

The targeted voucher system proposed here modifies the current system in the following important ways. First, public universities' students would have to pay tuition. In other words, public universities become paid universities, that is, the free-tuition regime disappears. Second, the resources saved by the government by not providing free higher education anymore are used to finance the vouchers system. Third, the recipients of the vouchers system are solely the individuals coming from low income families who do not have the sufficient resources to finance their higher education. Finally, the system promoves a competition among public and private universities. Students choose the best universities and the competitive advantage of the public universities related to the fact that they were free-tuition institutions ceases to exist.

With the new system, there are two possible scenarios, depending on the quality of the public universities vis-à-vis the private ones. In the first scenario, in the fields or areas that the public universities are better than the private ones, it is unlikely to have changes in the alloction of students among private and public universities. Students coming from private schools (and relatively high income families) would still be successful in the entrance exams to study in the public universities, on average, and are likely to maintain their decisions to study in these universities even if they are not free anymore. Students with enough resources would now pay the tuition in the public universities. The others, who also happen to pass the entrance exam, would receive vouchers from the government, which would allow them to keep attending the university. The

3 This section is based in Andrade (2008).

4 This data comes from the OECD. 
important difference now is that there would be resources, which were used to pay the tuition for individuals from high income families in the public universities, to finance the private university for individuals coming from low income families through vouchers who would not be able to do so under the previous system. The new system would promote two important changes. First, with vouchers, the limited resources are directed to those individuals who really need financial support to attend the university. As a consequence, it reduces the relationship between the student's family income and his capability of attending an university. That is, it increases the social mobility. Second, individuals who were not able to finance private tuition are now able to do under the new regime. There is an increase in the fraction of the labor force who are able to obtain an university degree. Therefore, there is an increase in the quality of the labor force.

In the second scenario, in the fields or areas that the public universities are worst than the private ones, it is likely to occur changes in the allocation of students among private and public universities. Students coming from private schools (and relatively high income families) would still be successful in the entrance exams to study in the public universities, on average, but they are unlikely to maintain their decisions and attend public universities because the latter have lost its competitive advantage of being free-tuition institutions. When faced with similar tuition, they would opt for the private ones. With respect to individuals coming from low income families, they would now have the option between a private or public university as the vouchers could finance either one. They would also opt for the private ones. The possible effect of the introduction of the targeted vouchers is the shut down of the less efficient institutions, a topic discussed in sections 4 and 5 below. Under this second scenario, as under the first, the same two important changes occur. First, vouchers direct resources to those individuals who really need financial support and increase social mobility. Second, there are two reasons for an improvement in the quality of the labor force. On the one hand, as before, there is an increase in the fraction of the labor force who are able to attend university. On the other hand, the quality of those institutions who survive under the competition among universities which is possible under the targeted voucher sysem is higher. As a consequence, the quality of education provided to the students are also greater.

In sum, the proposed system is more efficient than the current one because it can improve the quality of the labor force and promoter a greater social mobility.

\section{Chilean Experience}

The discussion in the previous section indicates that, at least theoretically, the introduction of targeted vouchers can lead to an improvement in the quality of the labor force and in social mobility. However, it is interesting to contrast this 
theoretical results with the empirical evidence in the school system in Chile ${ }^{5}$ in order to understand what can go wrong with the adoption in practice of a system with similarities with the one that we propose to the higher education sector in Brazil.

Chile adopted a nationalwide school choice system in 1981. This system had some important characteristics. First, parents received vouchers that could be used to finance their children's education either in a private or public school. Second, each school, private or public, would then receive the same per-student subsidy (or vouchers). In other words, its revenues depended on the number of enrolled students. Third, private schools were free to decide to participate in the program or not. If they decided not to enter, they could not count on public funds. Finally, each school had the right to define the way it would select its students if there were more students wanting to study there than slots available, that is, if there was excess of demand.

In reality, the system introduced free competition in the school system in Chile. As a result, there was a dramatic change in the market. Prior to the voucher system, Chile had three types of schools: the elite and unsubsidized private schools which accounted for about 6\% of enrollments; public schools which accounted for about $80 \%$ of all students; and subsidized private schools that did not charge tuition and were often religious that accounted for $14 \%$ of all students. The elite schools decided not to adhere to the voucher system.

With the voucher system, more than a thousand new private schools entered in the market. As a consequence, the percentage of students enrolled in public schools dropped to about 49\% in 2005, whereas the fraction of the subsidized private schools (private schools that adhered to the voucher system) reached about $42 \%$. The remaining students were enrolled in the elite schools ${ }^{6}$.

Due to this change in the system, it was expected an improvement in quality of education in Chile. The argument was the following. As a result of the competition among private and public schools and parents' freedom to choose their preferred school, the worst schools would lose students and would not survive as their funding were based on the number of students. The best schools would increase their market share, as parents would obvioulsy choose them as their children's schools. Student would benefit from the environment of better and more efficient schools, which were more capable in providing more value to their academic formation. Therefore, the expected result was an increase in the Chilean education quality. An indicator of this improvement would be students' performance in standardized tests.

5 Although we are contrasting the theoretical results in a targeted voucher system in the higher education with the Chilean voucher system experience in schools, it is important to remark that there is at least one important difference between them. It is the fact that it is mandatory for students to attend school whereas it is not for university students. This difference has important effects on the dynamics of each sector. See discussion about this topic in Friedman (1962).

6 For more details, see Mcewan et. al (2008). 
However, despite this dramatic change in the school market in Chile and its expectation, there was no important change in the education quality measured by the performance of its students in proficiency tests. Hisieh and Urquiola (2006) shows that the relative performance of Chilean students in international tests did not change in any important way from 1970 to 1999. In the last Programme for International Student Assessment (PISA) in 2006, Chile obtained the position 38 and 47, respectively, in reading and math out of 56 countries. Its results were below the OECD average and slightly above other Latin American countries that took part in the test'.

In retrospect, it is possible to identify one important flaw in the design of the vouchers system in Chile, with crucial impact on the results of the program. It is the fact that, in practice, there was no competition among private and public schools. The reason is that public schools faced "soft budget constraints" and did not stop operating and closed its doors even if they lost students. About this, Sapelli (2003) wrote: "No public schools have closed, because all the schools that lost students to private voucher schools received subsidies to pay the professors' salaries, when needed. Given this incentive structure, municipal schools facing competition from private voucher schools may prefer students to leave, since they keep their jobs, and teach smaller classes." Hence, the system was not propered designed and it should not come as a surprise the fact that it did not lead to the expected results in terms of increasing the education quality as discussed above.

Althought there is no evidence of improvement in the quality of education, there is evidence that there is an increase in welfare associated with the introduction of the vouchers system. Gallego and Hernando (2008), combining structural estimates of preferences and policy simulations, find that "school choice, at least as it has been implemented in Chile, increases overall student welfare, but there is a lot of heterogeneity in the size and even the sign of the welfare changes." They emphasize that the fact that the system introduced geographic mobility, that is, allowed parents to choose a school other than the one closest to their home, benefited the poor the most. About this issue, McEwan et. al (2008) indicates that "many households have taken advantage of choice to shift their children into subsidized private schools, and based on revealed preference, this must have improved their welfare".

There was another important consequence of the introduction of the vouchers system in Chile. With the school choice, there was a flow of the best public school students to private schools, a phenomenon called stratification. When faced with excess of demand, private school selected the best students because they are easier to teach and the costs to provide

7 For example, in reading and math, Uruguay, Mexico and Brazil obtained, respectively, the position $(42,42),(43,48)$ and $(49,54)$. 
education to them are lower. This strategy was the best and profit maximizing one for private schools, as the value of the vouchers was the same independently of the quality of the student. As the peer-effect is an important component in the educational process, the result was a greater disparity in the quality of public schools vis-à-vis the private ones ${ }^{8}$. This problem occurred due to another important flaw in the design of the voucher system, which was to allow schools to choose their students when there was excess of demand.

At least two features could have been incorporated in the system that would have mitigated or inhibited the stratification. First, the value of the voucher could have varied across students depending on their quality. Students coming from low income families on average with a lower level of preparation could have received high value vouchers. It could compensate the fact that it is costly to provide education to them and private schools would be more inclined to accept them as students when faced with excess of demand. Second, the government could have prohibited another selection mechanism other than lottery when a school faced excess of demand. For instance, after the introduction of a vouchers system in Sweeden in 1992, there is evidence that the public schools students' performance improved due to the greater competition ${ }^{9}$. One important feature of the system is that schools had little room to decide the rules to select its students.

In order to address the problems associated with the vouchers system in Chile discussed above, there is an ongoing debate on how to fix the problems. They range from distributing different vouchers values depending on the students' socioeconomics status (already approved in Congress) and prohibiting student selection by schools to eliminating for profit schools in the system. There is another important movement in the direction of stipulating specific studentd learning goals for each school, as it has been implemented in the public schools in Brazil ${ }^{10}$. Some of these changes seem to be going in the direction of correcting the the voucher system in Chile with potencial positive consequences in terms of improving the quality of the education.

The main lesson from the Chilean case is that the design of the proper system is fundamental to reach que desired results.

\footnotetext{
8 For an extensive discussion of the peer effect, see Winston, G. and Zimmerman, D. (2003). About the peer effect in the higher education sector in Brazil, see Andrade et. al (2009).

9 For details of the Swedish case, see Sandstrom and Bergstrom (2005).

10 For further discussion, see McEwan et. at (2008).
} 


\section{Model}

In this section, we develop a model to address two effects related to the introduction of a targeted voucher system in the Brazilian higher education sector. The first is the fact that, if a true competition occurs and no "soft budget constraints" exists as in the case of the school system in Chile as discussed above, less efficient institutions would not survive and would close its doors. The second is the welfare effects of the new system. There is a possibility that the new system benefit and harm different types of individuals. We now turn to present the main features of the model.

The model employs a two-period economy. There are two types of families, which differ by the parent's level of human capital. At time $t=0$, parent has either a high or a low level of human capital. Each parent works, receives wages, decides whether to send his child to university, consumes, and dies. At time $t=1$, the child becomes a worker with high or low level of human capital, depending on the educational decision of his parent, receives a wage, and consumes. The measure of each generation (and the number of workers in each period) is constant and is normalized to one. Let $n_{h, t}$ and $n_{l, t}$ be the fraction of individuals, respectively, with high and low levels of human capital at time $t$. Note that $n_{h, 0}=n_{h, 0}^{*}$ and $n_{l, 0}=n_{l, 0}^{*}$ are exogenously given, and $n_{h, 0}^{*}+n_{l, 0}^{*}=1$.

The schooling decision is not modeled here, as it is assumed that all children have a school degree and are able to attend university. However, they differ in their ability to perform well at university and become an individual with a high level of human capital. A child with ability a who attends a private university becomes an individual with high or low level of human capital, respectively, with probability $\pi_{p r}(a)$ and $\left(1-\pi_{p r}(a)\right)$. In the case of attending a public university, the equivalent probability can differ and is denoted by $\pi_{p u}(a)$. If the quality of the public university is greater than the private, then $\pi_{p u}(a)>\pi_{p r}(a)$, $\forall a$. The inequality reverses if the opposite holds, that is, if the private university has a higher quality. This feature of the model limits the heterogeneity to two levels of human capital, and therefore to two income levels, which simplifies the analysis. If a child does not attend university, he has the lower level of human capital with probability equal to one. Let $F($.$) be the$ distribution function for ability on the support $[0,1]$, and $f($.$) be the$ corresponding density function. As in Caucutt and Kumar (2003), the distribution is identical across types and within families of the same type, and all ability draws are independent of each other. ${ }^{11}$

11 In this paper, the term ability includes cognitive and non-cognitive abilities. See Cunha et al. (2006) for a lenght discussion on the impact of cognitive and non-cognitive abilities and parent's education on the student performance, as well as early and late investments in education affecting many individuals' behaviors and income. 


\section{Assumption 1:}

$a \in 0,1], 0 \leq \pi_{j}(a) \leq 1, \pi_{j}(a)>0, \pi_{j}^{\prime \prime}(a)<0, \forall a$, and $\pi_{j}(0)=0, j=p r, p u$.

Under the free tuition system (system $f$ ) in Brazil, there are a fixed number of places in public universities and the accepted students are those who achieve the highest scores in the entrance exam. In order to mimick this feature of the current system, it is assumed that this number is equal to $s(s<<1)$ and the students who achieve the highest scores are the ones with greater abilities. Hence, the $s$ individuals with greater ability obtain the right to attend the public university, independently of their family's income background. ${ }^{12}$ Formally, the ability ranges of the individuals from high and low income families who acquire the right to attend public university under system $f$ are, respectively, equal to $\left[a_{p u, h}^{f}, 1\right]$ and $\left[a_{p u, l}^{f}, 1\right]$, such that: $s=n_{l, 0}^{*} \int_{a_{p p u, h}}^{{ }_{f}^{f}} f(a) d a+n_{l, 0}^{*} \int_{a_{p u, l}}^{1} f(a) d a .^{13}$

Under system $f$, the parent whose child has ability $a$ and is one of the selected students to attend the public university has the following problem:

$\max _{p u, p r, s}\left\{u\left((1-\tau) w_{i, 0}\right)+\beta \pi_{p u}(a) u\left(w_{h, 1}\right)+\right.$

$\left.+\left(1-\pi_{p u}(a)\right) u\left(w_{l, 1}\right)\right]$;

$u\left((1-\tau) w_{i, 0}-E\right)+\beta\left[\pi_{p r}(a) u\left(w_{h, 1}\right)+\left(1-\pi_{p r}(a)\right) u\left(w_{l, 1}\right)\right] ;$

$\left.u\left((1-\tau) w_{i, 0}\right)+\beta u\left(w_{l, 1}\right)\right\}, i=h, l$.

where $\pi$ is the income tax, $\beta$ is the discount factor, $w_{i, t}$ is the wage of individual with $i$ level of human capital at time $t, u$ is the utility function with the usual properties, and $E$ is the private university tuition. The university tuition can be seen as the cost per student in terms of units of consumption. The first term in the parenthesis in the family's problem indicates the public university option. At $t=0$, the family consumes its wage net of taxes and sends its child to a free public university. At $t=1$, the child who becomes a worker either with high or low level of human capital earns his or her wage. The second term indicates the private university option. The difference with

12With assumption 2 below, the $S$ individuals with the highest abilities actually decide to attend the public universities under the free tuition regime.

13Note that $a>a_{p u, l}^{f}=a_{p u, h^{\prime}}^{f}$ 
respect to the first option is that the family pays both taxes and the cost of the private education $(E)$ at $t=0$, and the probability of the child becoming a worker is now based on the quality of the private university. The last term is the option of not sending the child to university at all. The family pays taxes and the child becomes a worker with low level of human capital. The other families, whose children are not among those selected to attend the public university, have a similar problem, with the difference that they do not have the first option of sending their children to public university. ${ }^{14}$

Under the targeted voucher system (system v), students have to pay tuition to attend either public or private universities. To simplify the analysis, I assume that private and public tuitions are equal $\left(E_{p r}=E_{p u}=E\right)$. It is important to define which low income families are eligible to receive the voucher $V$, where $V=E .^{15}$ They are the ones with the highest ability levels among those families who do not send their children to attend university without the financial aid from the government. I define the ability range of the individuals who receive vouchers as $\left[a_{\text {inf }}^{v}, a_{\text {sup }}^{v}\right]$. Total number of vouchers distributed are equal to $s$. Hence, $s=n_{l, 0}^{*} \int_{a_{\text {inf }}^{v}}^{a_{\text {sup }}^{v}} f(a) d a$. The number of places available in the public universities are still the same and equal to $s$. If public universities face excess demand, I assume that the individuals with the highest abilities have the right to attend them. However, the places available in the public universities may not be filled under the targeted voucher system as they are not free anymore and their quality may be lower than the private ones.

Under system $v$, the parent whose child has ability a has the following problem: $\max _{p u, p r, s}\left\{u\left((1-\tau) w_{i, 0}-E+V\right)+\beta \pi_{p u}(a) u\left(w_{h, 1}\right)+\right.$ $\left.+\left(1-\pi_{p u}(a)\right) u\left(w_{l, 1}\right)\right]$

$u\left((1-\tau) w_{i, 0}-E+V\right)+\beta\left[\pi_{p r}(a) u\left(w_{h, 1}\right)+\left(1-\pi_{p r}(a)\right) u\left(w_{l, 1}\right)\right] ;$ $\left.u\left((1-\tau) w_{i, 0}\right)+\beta u\left(w_{l, 1}\right)\right\}, i=h, l$.

$14 T o$ simplify the analysis, tuition $E$ is the only cost of higher education. To simplify the analysis, this paper ignores the opportunity cost of foregone earnings, an important component of the cost of education, as it does not affect the results. 15 For simplicity, I use a targeted voucher system in which all recipients receive vouchers with the same face value. For a further discussion on different voucher systems and its impacts, see Neal (2002) and Ladd (2002). 
where the first term is the option to send his child to a public university, the second is the private university option and the third one is the non-university option. For those families eligible to receive vouchers, $V=E$, and for the others $V=0$.

Recall that, independently of which system is in place, each family has to pay an income tax $(\pi)$ at $t=0$. Income tax are the sole source of revenues to the government. Under system $f$, public university students do not pay tuition which is financed by the government. Government expenditures are equal to $s E$. Under the system $v, s$ vouchers are distributed and each one has a face value equal to $E$. Total government expenditures are also equal to $S E$. As a result, the model is constructed in a way that total expenditures by the government are the same in both systems, which makes them comparable. Government's budget constraint, which has to be in equilibrium, is the following: $\tau\left(n_{h, 0}^{*} w_{h, 0}+n_{l, 0}^{*} w_{l, 0}\right)=s E$.

There is a single non-storable good in the economy produced by firms operating in a competititve market. There is no physical capital in the economy. The only inputs in the production process are the two types of labor, with high and low levels of human capital. The single technology, which has constant returns to scale, produces goods that can be consumed or invested in education and is as follows: $Y_{t}=A N^{\alpha}{ }_{h, t}\left(N_{h, t}+N_{l, t}\right)^{1-\alpha}$ where $A>0 ; 0<\alpha<1 ; N_{h, t}$ and $N_{l, t}$ are, respectively, the number of individuals with high and low levels of human capital employed in the production process at time $t$. The idea behind this production function is the following. Workers with high level of human capital provide two distinct productive services, physical effort (" brawn") and mental effort (" brains")". Workers with low level of human capital is capable of providing only the former. In other words, in order to be able to execute more sophisticated tasks the individual must acquire a higher level of human capital. ${ }^{16}$ It is easy to check that the greater is the fraction of individuals with high level of human capital, the greater is total production. Moreover, as each type of labor is paid its marginal product, $w_{h, t}$ is always greater than $w_{l, t^{*}}$

\section{Welfare Effects of Targeted Vouchers}

This section compares the individuals' economic welfare when system $f$ is replaced by system $v$. This comparison is performed under three possible scenarios. In scenario l, low income families' net wages $\left((1-\tau) w_{l, 0}\right)$ are greater than the university tuition $(E)$, that is, they are not credit constrained. There are three subcases: public universities have either higher, lower or the same 
quality as private universities $\left(\pi_{p r}(a) \leq \pi_{p u}(a), \forall a\right)$. In both scenarios II and III, low income families are credit constrained $\left((1-\tau) w_{l, 0}<E\right)$. The only difference between scenarios II and III is the quality of the public university vis-áa-vis the private one. In the former, public universities' quality is at least as great as the private universities' $\left(\pi_{p r}(a) \pi_{p u}(a), \forall a\right)$. In the latter, private universities are better $\left(\pi_{p r}(a)>\pi_{p u}(a), \forall a\right)$.

Before proceeding with the analysis, it is important to define the competitive equilibrium under both systems ${ }^{17}$ and show a result that is going to be useful below.

Definition 1: Given $E s, E, V$ and $n_{h, 0^{\prime}}{ }^{\prime}$ a competitive equilibrium under system $j$ is characterized by $n_{i, 1^{j}}^{j}, w_{i, 0^{\prime}}^{j} w_{i, 1^{\prime}}^{j} a_{p u, i}^{j}$ and $a_{p r, i}^{j}(i=h, l)$, and $a_{\text {inf }}^{v}$ and $a_{\text {sup }}^{v}$ under system v, such that: (i) given wages, firms maximize profits; (ii) the labor market clears, that is, $N_{h, t}=n_{h, t}^{j}$ and $N_{l, t}=n_{l, t}^{j}(t=0,1)$; (iii) $a_{p u, h}^{f}=a_{p u, l}^{f}$ is obtained from the following equation for $s, s=n_{h, 0}^{*} \int_{a}^{{ }^{f}}{ }_{a p u, h} f(a) d a+n_{l, 0}^{*} \int_{a_{p u, l}}^{1} f(a) d a$; (iv) given wages, $s, E$ and $V, a_{p u, i}^{j}$ and $a_{p r i}^{j}$ solve the university decision problem of family $i$ in ( ) such that individuals with ability ranges $\left[a_{p u, i}^{j} 1\right]$ and $\left[a_{p r i, i}^{j} a_{p u, i}^{j}\right]$ attend, respectively, public and private universities; $(v) a_{\text {sup }}^{v}$ and $a_{\text {inf }}^{v}$ are obtained, respectively, from the following equations, $a_{\text {sup }}^{v}=a_{p r l}^{v}$ and

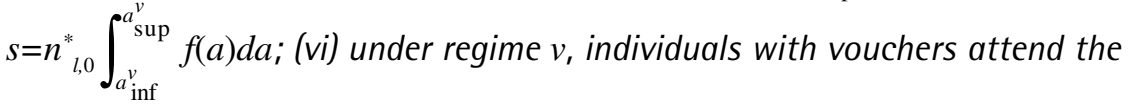
type of university with higher quality; (vii) the government's budget constraint is in equilibrium; and (viii) the law of motion for the variables $n_{h, t}^{f}$ and $n_{h, t^{\prime}}^{v}$ which are, respectively, given by:

$$
\begin{aligned}
& n_{h, l}^{f}=n_{h, 0}^{*}\left[\int_{a_{p u, h}^{f}}^{1} \pi_{p u}(a) f(a) d a+\int_{a_{p p h}^{f}}^{a_{p u, h}^{f}} \pi_{p r}(a) f(a) d a\right]+ \\
& +n_{l, 0}^{*}\left[\int_{a_{p u, l}^{f}}^{1} \pi_{p u}(a) f(a) d a+\int_{a_{p r, l}^{f}}^{a_{p u, l}} \pi_{p r}(a) f(a) d a\right],
\end{aligned}
$$

and 
$n_{h, 1}^{v}=n_{h, 0}^{*}\left[\int_{a^{v} p u, h}^{1} \pi_{p u}(a) f(a) d a+\int_{a_{p r, h}^{v}}^{a_{p u, h}^{v}} \pi_{p r}(a) f(a) d a\right]+$

$+n_{l, 0}^{*}\left[\int_{a^{f} p u, l}^{1} \pi_{p u}(a) f(a) d a+\int_{a_{p r l}^{f}}^{a_{p u, l}^{f}} \pi_{p r}(a) f(a) d a\right]+$

$\left.+\int_{a_{\mathrm{inf}}^{v}}^{a_{p r l}^{v}} \pi_{p r}(a) f(a) d a\right]$.

It is worth emphazising that, under system $v$, public university would not exist if a voucher system is introduced and the private university has a higher quality. It occurs because a voucher's recipient would be able to choose a place either in the private or public university and would certainly opt to the former one. The non-recipients devoided from the free tuition alternative in the public universities would also choose the private alternative. This possibility suggests that a government policy based on a targeted voucher regime may suffer opposition from members of low quality public universities.

Proposition 1: $n_{h, 1}^{v}>n_{h, 1}^{f}$.

The above result indicates that the fraction of individuals with high level of human capital at $t=1$ is greater under the system $v$ in comparison with the one under system $f$. The intution behind this result is the following. Under v, limited resources are directed only to those individuals who would not attend university otherwise. The effect is to decrease the skill premium, which indicates a greater quality of the labor force.

We are now ready to turn to the welfare analysis. The following proposition analyzes the welfare effects of the introduction of the targeted voucher system under scenario I (low income families are not credit constrained):

Proposition 2: With $(1-\tau) w_{l, 0}>E$ and $\pi_{p r}(a) \leq \pi_{p u}(a), \forall a$, high income families with child's ability $a$ : are better off if $a<a_{p r h}^{f}$; are worst off if $a>a_{p r h}^{v}$; may be better off or worst off if $a_{p r, h}^{v}>a>a_{p r, h}^{f}$ low income families with child's ability $a$ : are better off if $a<a_{p r, l}^{v}$; are worst off if $a>a_{p r, l}^{v}$.

The results are the same no matter which type of university, private or public, has a greater quality. With vouchers, those individuals either from low or high income families who were attending public university in the free tuition system 
are necessarily worst off (respectively with ability $a>a_{p u, l}^{f}$ and $a>a_{p u, h}^{f}$ ). There are two reasons. First, because they have to start paying the university tuition, either private or public depending on their choice. Second, because the voucher's system leads to a reduction in the skill premium and the potential benefit of attending university, as it increases the fraction of individuals with high level of human capital in the next period $\left(n_{h, 1}\right)$.

Individuals who attend private university in both systems (with free tuition and vouchers) and are not voucher's recipient are also necessarily worst off. They are the ones with ability $a, a_{p u, i}^{f}>a>a_{p r i}^{v}(i=h, l)$. They keep paying the same tuition but the expected utility of obtaining the university degree is reduced due to the lower skill premium. In contrast, the reduction in the skill premium benefits those individuals who do not attend university in either regime. These are the ones from low and high income families, respectively, with ability $a<a_{\text {inf }}$ and $a<a_{p r, h}^{f}$. Their wages inevitably augments as there is less individuals with low level of human capital.

It is not clear the welfare effects on those individuals from high income families who attend private university in the free tuition system and do not attend in the targeted voucher system (with ability $a, a_{p r, h}^{v}>a>a_{p r h}^{f}$ ). One the one hand, with the lower skill premium, it is not profitable anymore to pay for their education and obtain a lower immediate utility. On the other hand, they get a higher wage without investing in additional education. These two effects run in opposite directions and it is not clear the net effect.

Finally, individuals who either were attending private university or were not attending university in the free tuition system and start receiving vouchers are obviously better off. Their ability range is equal to $\left[a_{\mathrm{inf}}^{v}, a_{p r,}^{v}\right]$.

Proposition 3: With $(1-\tau) w_{l, 0}<E$ and $\pi_{p r}(a) \pi_{p u}(a), \forall a$, high income families with child's ability $a$ : are better off if $a<a_{p r, h}^{f}$; are worst off if $a>a_{p r, h}^{v}$; may be better off or worst off if $a_{p r, h}^{v}>a>a_{p r, h}^{f}$; low income families with child's ability $a$ : are better off if $a<a_{p u, l}^{v}$; are worst off if $a<a_{p u, l}^{f}$. 
The above proposition indicates the welfare effects of targeted vouchers under scenario II (low income families are credit constrained and public universities are at least as good as private ones). In comparison to the results in the previous proposition, the effects and its explanations are exactly the same. The only difference is that with credit constrained families, there is not the case in which individuals from low income families were attending private university in the free tuition system. Therefore, the ability of those individuals from low income families who are better off are formed by the intervals $\left[0, a_{\text {inf }}^{v}\right]$ and $\left[a_{\text {inf }}^{v}, a_{p u, l}^{f}\right]$ representing, respectively, those who do not attend university in either regime and who do not attend university in the free tuition regime and receive vouchers. The former are better off because their wages are greater. The latter are better off because they can now attend university without paying. The others are worst off.

Proposition 4: With $(1-\tau) w_{l, 0}<E$ and $\pi_{p r}(a)>\pi_{p u}(a), \forall a$, high income families with child's ability $a$ : are better off if $a<a_{p r, h^{f}}$; are worst off if $a>a_{p r, h^{v}}$; may be better off or worst off if $a_{p r, h}^{v}>a>a_{p r, h}^{f}$; low income families with child's ability $a$ : are better off if $a<a_{p u, l^{f}} ;$ may be better off or worst off if $a>a_{p u, l^{f}}$

Finally, the above proposition presents the welfare effects under scenario III (low income families are credit constrained and the private universities have a higher quality). There is only one diffence with respect to the case dealt in the previous proposition. It is not clear the welfare effects on low income families who have the right to attend public university in the free tuition system $\left(a>a_{p u, l}^{f}\right)$. On the one hand, when vouchers are introduced, they are worst off because the lower skill premium reduces the expected benefit from an university degree. On the other hand, they now have the choice due to the vouchers system to attend a private university which has a higher quality. As a result, it increases their probability of becoming an individual with high level of human capital and receiving a higher wage in the future. Hence, the net effect is ambiguous. 


\section{Conclusion}

There are some interesting points to stress as a result of the replacement of the free tuition system by the targeted voucher one. To begin with, the proposed system is more efficient than the current one because it can improve the quality of the labor force and promoter a greater social mobility.

Obviously, the welfare effects are not homogenous across individuals in the society. There are clear winners and losers. In general, one can say that the winners are the families whose children have lower ability levels, independently of their income. In addition, the losers are not only the students who lose their right to attend public university without paying tuition. They are also individuals who were attending private university in the free tuition regime. Their losses are related to the fact that vouchers increase the quality of the labor force in the future, reducing the potential benefit of investing and acquiring an university degree. Finally, the clear beneficiaries of the voucher system are families who are not able to send their children to attend university either in the free tuition or voucher regimes. They benefit due to the reduction in the skill premium.

If a majority voting mechanism was in place to decide the university system in Brazil, the analysis developed above indicates that a targeted voucher system would replace the free-tuition one. The reason is that the majority, who do not attend university, would benefit due to the reduction in the skill premium. The fact that there is no movement in this direction may be explained by the opposition of those who are hurt by the change. Among those are also the members of low quality public universities which would not survive under the targeted voucher system.

Finally, it is important to emphasize, though, what we have learnt from the Chilean experience. Without a proper design of the vouchers system, the expected results related to the introduction of the voucher system may not occur. It is very important to pay attention to the details of the program when implemented. 


\section{References}

ALBRECHT, D.; ZIDERMAN, A. Funding mechanisms for Higher Education. Washington, D.C: World Bank, 1992. (Discussion Papers;153).

ANDRADE, E. Growth, distribution, and school policy. 1998. Doctoral (Dissertation) - University of Chicago, Chicago, IL, 1998.

ANDRADE, E. Higher Education: (Almost) Free Tuition vs. Quotas vs. Targeted Vouchers. São Paulo, 2008. Mimeografado.

ANDRADE, E.; MOITA, R.; SILVA, C. Peer effect and competition in Higher Education. São Paulo, 2009. Mimeografado.

CAUCUT, E.; KUMAR, K. Higher Education subsidies and heterogeneity: a dynamic analysis. Journal of Economic Dynamic \& Control, n. 27, p. 1459-1502, 2003.

CHAPMAN, B. Income contingent loans for Higher Education: international reforms. In: HANUSHEK, E.; WELCH, F. Handbook of the economics of education. North Holland: Elsevier, 2006. v. 2

Chen, Z.; West, E. Selective versus universal vouchers: modeling median voter preferences in education. American Economic Review, v. 90, n. 5, 2000.

CREEDY, J.; FRANÇOIS, P. Financing Higher Education and majority voting. Journal of Public Economics, 1990.

CUNHA, F. et al. Interpreting the evidence on life cycle skill formation. Cambridge, MA: NBER, 2006. (Working Paper; 1331).

FERNANDEZ, R.; ROGERSON, R. On the political economy of education subsidies. Review of Economic Studies, v. 62, p. 249-262, 1995.

FRIEDMAN, M. Capitalism and freedom. Chicago, IL: Chicago University Press, 1962.

GALLEGO, F.; HERNANDO, A. On the determinants and implications of school choice: semi-structural simulations for Chile. Santiago, Chile: Instituto de Economia, Pontificia Universidad Católica de Chile, Fall 2008. (Documento de trabajo; 343).

JOHNSON, G. Subsidies for Higher Education. Journal of Labor Economics, 1984. 
LADD, H. School vouchers: a critical view. Journal of Economic Perspectives, v. 16, n. 4, Fall 2002.

MCEWAN, P.; URQUIOLA, M.; VEGAS, E. School choice, stratification, and information on school performance: lessons from Chile. Economia, v. 8, n. 2, 2008.

NEAL, D. How vouchers could change the market for education. Journal of Economic Perspectives, v. 16, n. 4, Fall 2002.

SAPELLI, C. The chilean voucher system: some new results and research challenges. Cuadernos de Economía, Año 40, n. 121, Diciembre. 2003.

STOKEY, N. Free trade, factor returns, and factor accumulation, Journal of Economic Growth, v. 1, n. 4, p. 421-47, Dec. 1996.

VELOSO, F.; FERREIRA, S. A escassez de educação. In: GIAMBIAGI, F.; VILLELA, A. (Org.). Economia brasileira contemporânea, 1945-2004. São Paulo: Elsevier, 2006.

WINSTON, G.; ZIMMERMAN, D. Peer effects in Higher Education. Cambridge, MA: NBER, 2003. (Working paper; 9501).

Recebido: 06/04/2009

Aceito para publicação em: 13/09/2009 


\section{Appendix}

Proposition 1: $n_{h, 1}^{v}>n_{h, 1}^{f}$.

Proof. This proposition is valid with $(1-\tau) w_{l, 0} \leq E$ and $\pi_{p r}(a) \leq \pi_{p u}(a)$. The proof is analogous in all possible cases. I show here the case in which low income families are not credit constrained $\left((1-\tau) w_{l, 0}>E\right)$ and public universities have a greater quality $\left(\pi_{p u}(a)>\pi_{p r}(a)\right)$, and compare the regimes.

The following condition must hold in the competitive equilibrium under regime $j$ $(j=f, v)$ :

$\beta \pi_{p r}\left(a_{p r, i}^{j}\right)\left[u\left(w_{h, 1}\right)-\left(w_{l, 1}\right)\right]=u\left((1-\tau) w_{i, 0}\right)-u\left((1-\tau) w_{i, 0}-E\right) \equiv A_{i}$.

I need to show that $a_{p r, i}^{v}<a_{p r, i}^{f}(i=h, l)$ and $a_{p r, l}^{f}>a^{v}{ }_{\text {inf }}$. Suppose that $a_{p r, i}^{v}=a_{p r, i}^{f}$ Then:

$$
\begin{aligned}
& n_{h, 1}^{f}=n_{h, 0}^{*}\left[\int_{{ }_{a p u, h}^{f}}^{1} \pi_{p u}(a) f(a) d a+\int_{a_{p r, h}^{f}}^{a_{p u, h}^{f}} \pi_{p r}(a) f(a) d a\right]+ \\
& +n^{*}\left[\int_{a^{f} p u, l}^{1} \pi_{p u}(a) f(a) d a+\int_{a_{p r, l}^{f}}^{a_{p u, l}^{f}} \pi_{p r}(a) f(a) d a\right]<n_{h, 1}^{\prime}= \\
& +n_{h, 0}^{*}\left[\int_{a^{f} p u, h}^{f_{p u}} \pi_{p u}(a) f(a) d a+\int_{a_{p r, h}^{f}}^{a_{p u, h}^{f}} \pi_{p r}(a) f(a) d a\right]+ \\
& +n^{*}\left[\int_{l, 0}^{1}{ }_{a_{p u, l}^{f}}^{f} \pi_{p u}(a) f(a) d a+\int_{a_{p r, l}^{f}}^{a_{p u, l}^{f}} \pi_{p r}(a) f(a) d a\right] \\
& \left.+\int_{a_{\text {inf }}^{v}}^{a}{ }_{p r l} \pi_{p r}(a) f(a) d a\right]
\end{aligned}
$$

wheres $=n_{l, 0}^{*} \int_{a}^{a_{\text {inf }}^{f}} \pi_{p r l}^{f}(a) f(a) d a$, and $n_{h, 1^{\prime}}$, the fraction of individuals with high level of human capital at $t=1$ when $a_{p r, i}^{v}=a_{p r, i}^{f}$ under the system $v$, is greater than $n_{h, 1^{\prime}}^{f}$ as the vouchers' recipients are now attending university. As $n_{h, 1}^{\prime}>n_{h, 1^{\prime}}^{f}$ then $w_{h, 1}^{f}>w_{h, 1}^{\prime}$ and $w_{l, 1}^{f}<w_{l, 1^{\prime}}^{\prime}$ where $w_{i, 1}^{\prime}$ is the wage of individual type $i$ at $t=1$ under system $v$ when $a_{p r, i}^{f}=a_{p r, i}^{v}$. It means that the skill premium is lower. Hence, the combination $a_{p r, i}^{f}=a_{p r, i}^{v}$ and $w_{h, i}^{v}=w_{h, i}^{\prime}$ do not satisfy equation (5) that must hold in the competitive equilibrium under regime $v: \beta \pi_{p r}\left[u\left(w_{h, 1}^{\prime}\right)-u\left(w_{l, 1}^{\prime}\right)\right]<A_{i}$. 
Hence, and $w_{i, 1}^{\prime}$ are not part of the competitive equilibrium under system $v$. To restore equality, the LHS must be greater, that is, the ability of those individuals coming from high and low income families must be greater, which increases the skill premium (without returning to the previous level, though). Therefore, $a_{p r, i}^{v}>a_{p r, i^{\prime}}^{f} a_{p r, l}^{f}>a_{\text {inf }}^{v}$ and $n_{h, 1}^{v}>n_{h, 1}^{f}$.

Proposition 2: With $(1-\tau) w_{l, 0}>E$ and $\pi_{p r}(a) \leq \pi_{p u}(a), \forall a$, high income families with child's ability $a$ : are better off if $a<a_{p r, h}^{f}$; are worst off if $a>a_{p r, h}^{v}$; may be better off or worst off if $a_{p r, h}^{v}>a>a_{p r, h}^{f}$; low income families with child's ability $a$ : are better off if $a<a_{p r, l}^{v}$; are worst off if $a>a_{p r, l}^{v}$.

Proof. Let's first compare the welfare for those individuals from high income families. Individuals with $a<a_{p r h}^{f}$ are better off because: $u\left((1-\tau) w_{h, 0}\right)+\beta u\left(w_{l, 1}^{v}\right)>u\left((1-\tau) w_{h, 0}\right)+\beta u\left(w_{l, 1}^{f}\right)$ as $n_{h, 1}^{v}>n_{h, 1}^{f}$ which implies that $w_{l, 1}^{v}>w_{l, 1}^{f}$. Individuals with $a>a_{p u, h}^{f}$ are worst off because:

$u\left((1-\tau) w_{h, 0}\right)+\beta\left[\pi_{p u}(a) u\left(w_{h, 1}^{f}\right)+\left(1-\pi_{p u}(a)\right) u\left(w_{l, 1}^{f}\right)\right]$

$>u\left((1-\tau) w_{h, 0}-E\right)+\beta\left[\pi_{k}(a) u\left(w_{h, 1}^{v}\right)+\left(1-\pi_{k}(a)\right) u\left(w_{l, 1}^{v}\right)\right],(k=p r, p u)$, as $n_{h, 1}^{v}>n_{h, 1}^{f}$ which implies that $w_{l, 1}^{v}>w_{l, 1}^{f}$ and $w_{h, 1}^{v}<w_{h, 1^{\prime}}^{f}$ and using assumption 2. Individuals with $a_{p u, h}^{f}>a>a_{p r, h}^{v}$ are worst off because: $u\left((1-\tau) w_{h, 0}-E\right)+\beta\left[\pi_{p r}(a) u\left(w_{h, 1}^{f}\right)+\left(1-\pi_{p r}(a)\right) u\left(w_{l, 1}^{f}\right)\right]$ $<u\left((1-\tau) w_{h, 0}-E\right)+\beta\left[\pi_{p r}(a) u\left(w_{h, 1}^{v}\right)+\left(1-\pi_{p r}(a)\right) u\left(w_{l, 1}^{v}\right)\right]$ as $n_{h, 1}^{v}>n_{h, 1}^{f}$ which implies that $w_{l, 1}^{v}>w_{l, 1}^{f}$ and $w_{h, 1}^{v}<w_{h, 1}^{f}$. Individuals with $a_{p r h}^{v}>a>a_{p r, h}^{f}$ may be better off or worst off depending on the sign of the following inequality:

$$
\begin{aligned}
& u\left((1-\tau) w_{h, 0}-E\right)+\beta\left[\pi_{p r}(a) u\left(w_{h, 1}^{f}\right)+\left(1-\pi_{p r}(a)\right) u\left(w_{l, 1}^{f}\right)\right] \\
& \leq u\left((1-\tau) w_{h, 0}\right)+\beta u\left(w_{l, 1}^{v}\right)
\end{aligned}
$$

The result is uncertain as $w_{l, 1}^{v}>w_{l, 1}^{f}$. The proofs are similar for those individuals from low income families. 
Proposition 3: With $(1-\tau) w_{l, 0}<E$ and $\pi_{p r}(a) \pi_{p u}(a), \forall a$, high income families with child's ability $a$ : are better off if $a<a_{p r, h}^{f}$ are worst off if $a>a_{p r, h}^{v}$; may be better off or worst off if $a_{p r, h}^{v}>a>a_{p r, h}^{f}$ i low income families with child's ability $a$ : are better off if $a<a_{p u, l}^{f}$; are worst off if $a>a_{p u, l}^{f}$.

Proof. The proofs are similar to the ones in proposition 2. The only exception is related to low income families with child's ability in the range $\left[a_{\text {inf }}^{v}, a_{p u, l}^{f}\right]$.

Those families are better off because:

$u\left((1-\tau) w_{l, 0}\right)+\beta u\left(w_{l, 1}^{f}\right)<u\left((1-\tau) w_{l, 0}\right)+\beta\left[\pi_{p r}(a) u\left(w_{h, 1}^{v}\right)+\left(1-\pi_{p r}(a)\right) u\left(w_{l, 1}^{v}\right)\right]$ as $w_{l, 1}^{f}<w_{l, 1}^{v}$.

Proposition 4: With $(1-\tau) w_{l, 0}<E$ and $\pi_{p r}(a)>\pi_{p u}(a), \forall a$, high income families with child's ability $a$ : are better off if $a<a_{p r, h}^{f}$; are worst off if $a>a_{p r, h}^{v}$; may be better off or worst off if $a_{p r, h}^{v}>a>a_{p r, h}^{f}$; low income families with child's ability $a$ : are better off if $a<a_{p u, l}^{f}$; may be better off or worst off if $a<a_{p u, l}^{f}$.

Proof. The proofs are similar to the ones in proposition 3. The only exception is related to low income families with child's ability in the range $\left[a_{p u, l}^{f}, 1\right]$. Those families may be better off or worst off, depending on the sign of the following inequality:

$u\left((1-\tau) w_{l, 0}\right)+\beta\left[\pi_{p, u}(a) u\left(w_{h, 1}^{f}\right)+\left(1-\pi_{p, u}(a)\right) u\left(w_{l, 1}^{f}\right)\right]$ $\leq u\left((1-\tau) w_{l, 0}\right)+\beta\left[\pi_{p r}(a) u\left(w_{h, 1}^{v}\right)+\left(1-\pi_{p r}(a)\right) u\left(w_{l, 1}^{v}\right)\right]$

The result is uncertain as $\pi_{p r}(a)>\pi_{p u}(a), \forall a$ and $w_{l, 1}^{v}>w_{l, 1}^{f}$ and $w_{h, 1}^{v}>w_{h, 1}^{f}$. 